\title{
Effectiveness of Honey and Aloe Vera on the Post Extraction Healing Among Young Adults: A Randomized Clinical Trial
}

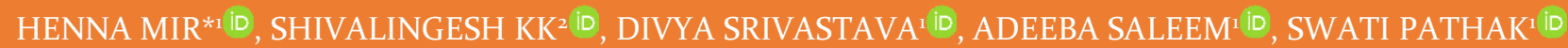

INTRODUCTION: "Dry socket" was first described by Crawford in literature in 1896 . When people are recognizing that current medicine is not the soul cure for diseases, we look back to the past for potential remedies with the least possible side-effectiveness. So the objective of this study was to evaluate the effectiveness of honey and aloevera on healing of post extraction wounds.

MATERIAL AND METHODS: Honey and aloe-vera were prepared by mixing with sterilized cotton. The socket involved was separated by dry autoclaved cotton rolls from the rest of the oral cavity, then honey/aloe-vera was inserted into the respective groups. All patients were advised to avoid solid and liquid diets for 30 minutes after the treatment. Dressings were changed on 3 rd day and on 7 th day and sockets were evaluated.

RESULTS: When the intra-group comparison of honey ( $\mathrm{p}$-value=0.003) and aloe-vera ( $\mathrm{p}$-value=0.0oo) was done, both were found to be statistically significant in the healing of dry socket. When the inter-group comparison was done between honey and aloe-vera, Aloe-vera had high healing capacity and was found to be highly statistically significant ( $\mathrm{p}$-value=0.001).

DISCUSSION: When the intra-group comparison of honey and aloe-vera was done, both were found to be statistically significant in the reduction of dry socket. When the inter-group comparison was done between honey and aloe-vera, Aloe-vera had high healing capacity and was found to be highly statistically significant ( $\mathrm{p}$-value=0.0o).

CONCLUSION: From the analysis, it can be inferred that aloe vera and honey are healthy, natural and user-friendly substitute adjuncts that might be feasible to promote healing of extraction sockets.

KEYWORDS: Tooth Extraction, Wound Healing, Clinical Trial

\section{INTRODUCTION}

"Dry socket" was first described by Crawford in literature in 1896. Since then, other terms have been used to refer to this complication, such as "alveolar osteitis", "alveolitis", "localized osteitis", "alveolitis sicca dolorosa", "localized alveolar osteitis", "fibrinolytic alveolitis", "septic socket", "necrotic socket", and "alveolalgia". "There is a loss of clot from the socket in this condition. Postoperative clinical discomfort can vary from basic local inflammation to typical alveolar osteitis, including halitosis, regional trismus, empty socket irradiating dull throbbing pain, usually to the ipsilateral ear, temporal zone, or eye. Some of the essential etiological considerations are oral microorganisms, trauma during procedure, root and bone fragments left in the cavity, repeated curettage and irrigation, blood clot dislodging, oral contraceptives and smoking. In normal dental extractions, the incidence of alveolar osteitis has been reported in the range of 0.5 percent- 5 percent, but 1 percent-37.5 percent higher incidence of alveolar osteitis is recorded with the extraction of mandibular third molars. ${ }^{2}$

Every dry socket management technique is considered effective if it increases the patient's quality of life while lowering the expense of treatment and reducing the patient's pain. Copious irrigation with warm saline or dilute hydrogen peroxide extraction socket and dressing with obtundent medication are some of the known dry socket treatment modality but have their limitations of prolonged and repeated patient visits to complete treatment. The topical application of a mixture of eugenol, benzocaine and Peruvian balsam ${ }^{3}$, iodoform and butylparaminobenzoate and prophylactic administration of antibiotics containing systemic beta-lactamase inhibitor showed a drop in dry socket incidence. ${ }^{4,5}$

The use of various natural medicines in the field of dentistry has been supported by recent development and success in the field of alternative medicine. The use of natural products in the prevention and care of oral disorders may be useful for urban and rural populations at a low socioeconomic level. "Honey" \& "Aloevera" are the most common and attracting a lot of scientific attention among the numerous herbal agents currently available. ${ }^{6}$

The honey dry socket philosophy was drawn from fundamental science and clinical study of rapid 
epithelization of tissue injuries, covering the wound with honey retards tissue oxygenation by shielding the injured mucosa from air (oxygen) that would dampen pain within 30 seconds after application. ${ }^{7}$ More recently, about 60 species of bacteria have been documented to be inhibited by honey, including aerobes and anaerobes, gram-positive and gramnegative micro-organisms. ${ }^{6}$

On the other hand, the name Aloe vera is derived from the Arabic word "Alloeh" meaning "shining bitter substance," while "vera" in Latin means "true." Aloe vera gel (or mucilage) is a smooth, thin, tasteless, jellylike substance making up the inner parenchymal tissue component of the aloe leaves. This tissue is retrieved from the leaf by removing the gel from the inner cellular substance. $^{6}$

When people are recognizing that current medicine is not the soul cure for diseases, we look back to the past for potential remedies with the least possible sideeffectiveness. So, the objective of this study was to evaluate the effectiveness of honey and aloevera on healing of post extraction wounds.

\section{MATERIAL AND METHODS}

This study was conducted in the Department of Public Health Dentistry in collaboration with Department of Oral Medicine \& Radiology and Department Of Oral Surgery. After receiving ethical clearance, twenty dry socket patients were recruited for the research. The clinical criterion for dry socket was based on the following: two or three days of extraction and pain history, clinical assessment for sensitivity on gentle probing, trismus, halitosis and state of the tooth socket, i.e. bare bone and blood clot breakdown.

The research excluded the patients with systemic conditions such as diabetes mellitus, hepatic dysfunction, blood dyscrasia, bleeding problems, prior use of dry socket systemic antibiotics and background of all forms of tobacco use. After explaining the risks and benefits involved with treatment, informed consent was taken from the patients.

It was observed that the dry sockets were filled with food remains, soft plaque, bony flecks, or other residue from the tooth or calculus. The socket was then irrigated completely with normal saline. The bare bone was exposed without any covering of healing granulation tissue. Simple randomization technique was followed and the patients were divided into two groups.

Group 1: 10 post extraction sockets were treated with honey application.

Group 2: 10 post extraction sockets were treated with aloe-vera application.

Honey and aloe-vera were prepared by mixing with sterilized cotton. The socket involved was separated by dry autoclaved cotton rolls from the rest of the oral cavity, then honey/aloe-vera was inserted into the respective groups. All patients were advised to avoid solid and liquid diets for 30 minutes after the treatment. Dressings were changed on $3^{\text {rd }}$ day and on $7^{\text {th }}$ day and sockets were evaluated.

Healing potential was assessed using the standardised index by Landry, Turnbull and Howley Scores.

Healing Index 1: Very Poor Has 2 or more of the following:

- Tissue color: $>=50 \%$ of gingiva red

- Response to palpation: bleeding

- granulation tissue: present

- incision margin: not epithelialized, with loss of epithelium beyond incision margin

- suppuration present

\section{Healing Index 2: Poor}

- tissue color: $>=50 \%$ of gingiva red

- response to palpation: bleeding

- granulation tissue: present

- incision margin: not epithelialized, with connective tissue exposed

\section{Healing Index 3: Good}

- tissue color: $>=25 \%$ and $<50 \%$ of gingiva red

- response to palpation: no bleeding

- granulation tissue: none

- incision margin: no connective tissue exposed

\section{Healing Index 4: Very Good}

- tissue color: $<25 \%$ of gingiva red

- response to palpation: no bleeding

- granulation tissue: none

- incision margin: no connective tissue exposed

\section{Healing Index 5: Excellent}

- tissue color: all tissues pink

- response to palpation: no bleeding

- granulation tissue: none

- incision margin: no connective tissue exposed ${ }^{7}$ 
Statistical analysis: The data was entered on the Microsoft Excel spreadsheet and imported for statistical analysis into the Statistical Package for Social Sciences (SPSS) version 22. Significant differences were observed by applying the paired-t test and Independent t-test. Statistical significance was set at P-value less than 0.05 .

\section{RESULTS:}

In the present study, 20 patients were selected in which 10 were males and 10 were females (table 1 ).

\begin{tabular}{|c|c|c|}
\hline \multicolumn{3}{|c|}{ Total number of Patients } \\
\hline Gender & Number & Total \\
\hline Male & 10 & 20 \\
\hline Female & 10 & \\
\hline
\end{tabular}

Table 1. Distribution of study subjects

There were twelve patients who complained of pain, five patients had necrotic slough and three patients had halitosis (table 2).

\begin{tabular}{|c|c|c|}
\hline \multicolumn{3}{|c|}{ Clinical symptoms } \\
\hline S.no. & Symptom & $\begin{array}{c}\text { No. of } \\
\text { Patients }\end{array}$ \\
\hline $\mathbf{1}$ & Pain & $\mathbf{1 2}$ \\
\hline $\mathbf{2}$ & $\begin{array}{c}\text { Necrotic } \\
\text { slough }\end{array}$ & 5 \\
\hline 3 & Halitosis & 3 \\
\hline
\end{tabular}

Table 2. Clinical symptoms study subjects

Among the 20 teeth, only six teeth were maxillary molars (Four Maxillary Right Third Molar, Two Maxillary Left Third Molar) and the rest of 14 teeth were mandibular molars (Six Mandibular Left Third Molar, Eight Mandibular Right Third Molar, table 3).

\section{Tooth number}

1. Maxillary Right Third Molar

2. Maxillary Left Third Molar

3. Mandibular Left Third Molar

4. Mandibular Right Third Molar

Table 3. Distribution of the teeth involved in the study

When the intra-group comparison of honey (pvalue $=0.003)$ and aloe-vera $(p$-value $=0.000)$ was done, both were found to be statistically significant in the healing of dry socket (table4).

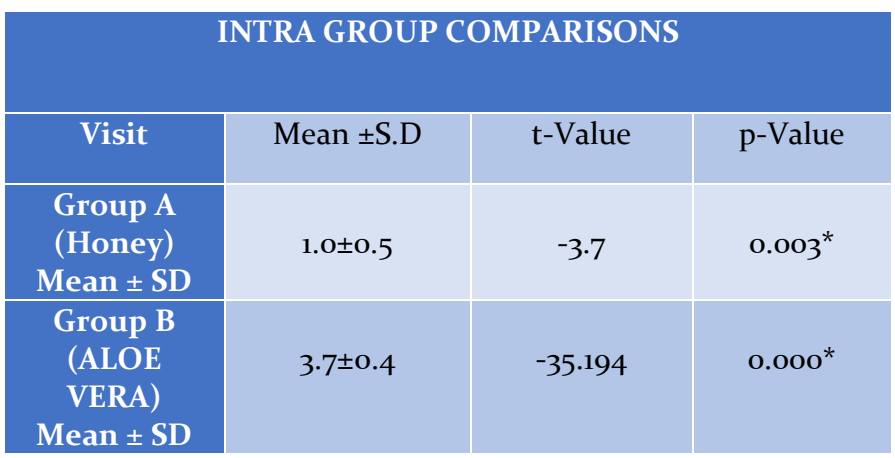

Table 4. Intra-group comparison of honey (p-value=0.003) and aloe-vera. [Paired t-test; $\mathrm{p}$-value $\leq 0.05$ (statistically significant)]

When the inter-group comparison was done between honey and aloe-vera, Aloe-vera had high healing capacity and was found to be highly statistically significant ( $\mathrm{p}$-value $=0.001$, table 5 ).

\section{DISCUSSION}

During dentoalveolar surgery, the appearance of dry sockets are common. This develops during the healing process of extraction socket which is most common following complicated extractions. The dry socket results in the extraction socket's delayed wound healing and its aetiology is not apparent. It is thought to arise because of the elevated degree of fibrinolytic involvement in the extraction socket, resulting in blood clot lysis, resulting in bone exposure. Dry socket pain occurs due to the release of kinins readily accessible during tissue damage, sensitivity to nerve endings to air, food and fluids in the extraction socket's bare bone, and an autoimmune mechanism that produces pain mediators and tissue activators. Because of more vascularization of maxilla than mandible, dry socket is more frequent in mandible than maxilla. Molars are often more affected because their sockets have broader circumferences that contribute to greater blood clots than other teeth that are likely to expose the blood clots to more fibrinolytic action. ${ }^{1}$

In folk medicine, herbal ingredients have been used for many years. Honey has an active antibacterial ability to cure periodontal diseases and mouth ulcers by fighting oral infections. Honey was used to heal contaminated wounds as long ago as 2000 years before bacteria were found to be the cause of infection. Honey was identified by Dioscorides in $50 \mathrm{AD}$ as being good for all rotten and hollow ulcers. Honey has been reported to have an inhibitory effect on about 6o species of bacteria, including aerobes and anaerobes, gram-positive and gram-negative microorganisms. ${ }^{8}$ Antibiotic resistant strains of bacteria (MRSA and VRE) have been found to 


\begin{tabular}{|c|c|c|c|c|}
\hline Visit & $\begin{array}{c}\text { Group A } \\
(\text { Honey) } \\
\text { Mean } \pm \text { SD }\end{array}$ & $\begin{array}{c}\text { Group B } \\
(\text { ALOE VERA) } \\
\text { Mean } \pm \text { SD }\end{array}$ & t-Value & p-Value \\
\hline $1^{\text {st }}$ day Visit & $1.5 \pm 0.5$ & $1.3 \pm 0.4$ & 1.2 & 0.206 \\
\hline $3^{\text {rd }}$ day Visit & $3.1 \pm 0.55$ & $3.3 \pm 1.0$ & -0.9 & 0.350 \\
\hline $7^{\text {th }}$ day Visit & $4.3 \pm 0.8$ & $4.0 \pm 0.1$ & $-3 \cdot 9$ & $0.001^{*}$ \\
\hline
\end{tabular}

Table 5. Inter-group comparison of honey ( $\mathrm{p}$-value=0.003) and aloe-vera. [Independent t-test; $\mathrm{p}$-value $\leq 0.05$ (statistically significant)]

be just as sensitive to honey as the antibiotic sensitive strains of the same species ${ }^{9}$, and there have been clinical records of wounds contaminated with MRSA being healed of infection and cured by application of honey. ${ }^{10,11,12}$ Hassan $S$ et al. ${ }^{2}$ conducted a study in which honey was found to be significantly effective in the healing of dry socket.

The aloe vera plant has been known and used for decades for its medicinal and skin care properties. The name Aloe vera is derived from the word "Alloeh" in Arabic, meaning sparkling bitter material, while "vera" means true in Latin. Aloe vera was used as the universal panacea by Greek scientists. Use of aloe-vera as a herbal remedy in dental conditions is increasing because of its proven anti-inflammatory, antiviral, antibacterial and antioxidative effects. ${ }^{13}$ The healing ability of aloe vera can be due to a variety of reasons, but the three important factors are:

1. Pain \& inflammation Inhibition.

2. Fibroblasts Stimulation to functionally produce proteoglycans \& collagen

3. Increase the tensile strength of the wound ${ }^{14}$

The fibroblast stimulation of Aloe vera produces and contributes additional collagen to the tissue during the healing process. Macrophages can also secrete substances which can activate fibroblasts in a similar way. New collagen forms between the margins of wounds when Aloe is present, whether the effect is direct (from Aloe) or indirect (from microphages). The improved tensile strength is mainly attributed to these collagen bonds. Thus, if the tensile strength increases, it is believed that Aloe increases the development of collagen.

Aloe vera gel contains a glycoprotein with cell proliferating-promoting activity and it has also been noted that aloe vera gel improved wound healing by increasing blood supply, which in turn resulted in increased oxygenation. Thompson reported in 1991 that topical use of allantoin gel extracted from aloe vera promoted the activity of fibroblasts and the proliferation of collagen. ${ }^{15}$

In the current study, 20 patients were selected in which 10 were males and 10 were females. Among the 20 teeth, only six teeth were maxillary molars (Four Maxillary Right Third Molar, Two Maxillary Left Third Molar) and the rest (14 teeth) were mandibular molars (Six Mandibular Left Third Molars, Eight Mandibular Right Third Molars).

When the intra-group comparison of honey and aloevera was done, both were found to be statistically significant in the reduction of dry socket which was in accordance to Hassan S et al. ${ }^{2}$, Ansari A et al. ${ }^{16}$ (for honey); Hemlatha R et al. ${ }^{6}$, Syafilda et al. ${ }^{17}$ and Nimma $\mathrm{LV}$ et al. (for aloe-vera). ${ }^{18}$

However when the inter-group comparison was done between honey and aloe-vera, Aloe-vera had high healing capacity and was found to be highly statistically significant ( $\mathrm{p}$-value $=0.001$ ). A study by Hemalatha $\mathrm{R}$ et al. ${ }^{6}$, who compared Aloe vera and honey on the post extraction wounds have used both drugs together implicating the importance of these herbs with no much clarity between the efficacy of Aloe vera or honey playing important role in healing.

\section{Limitations of the study:}

- We could show better results if we increase the sample size.

- Review of literature reveals no data on the comparison of honey and aloe vera for the treatment of dry socket.

Therefore, more clinical trials with larger sample size 
should be carried out.

\section{CONCLUSION}

From the analysis, it can be inferred that aloe vera and honey are healthy, natural and user-friendly substitute adjuncts that might be feasible to promote healing of extraction sockets. In order to ensure efficacy with these therapeutic agents, careful diagnosis, better understanding of herbal medicine and the application of that knowledge in treatment planning are necessary. Thus, herbal medicines will have a very important role in dentistry in times to come.

\section{REFERENCES}

1. Passi D, Singh G, Dutta S, Sharma S, Mishra S, Gupta C. Honey Extract as Medicament for Treatment of Dry Socket: An Ancient Remedy Rediscovered-Case Series and Literature Review. Journal of Maxillofacial Oral Surgery 2014;15(3):345.

2.Hassan S, Shah A, Hakim T, Teli Z. Honey in the Management of Dry Socket. International medical and Dental Research 2016;2(1):255-7.

3. Peterson LJ, Ellis E, Hupp JR, Tucker MR (2003) Contemporary oral and maxillofacial surgery $\left(4^{\text {th }} \mathrm{edn}\right)$. USA: Mosby 236-237

4. Cawson RA, Odell EW, Porter S (2002) Cawson's essentials of oral pathology and oral medicine, $7^{\text {th }}$ edn. Churchill Livingstone, Spain.

5. Delilbasi C, Saracoglu U, Keskin A. Effect of $0.2 \%$ chlorhexidine gluconate and amoxicillin plus clavulanic acid on the prevention of alveolar osteitis following mandibular third molar extractions. Oral Surgery Oral Medicine Oral Pathology Oral Radiology and Endodontics 2002;94:301-4.

6. Hemalatha R, Hemagaran G. Effectiveness of Honey and Aloe Vera on Post Extraction Healing. Journal of Dental and Medical Sciences 2015; 14(5):123-8.

7. Bergman A, Yanai J, Weiss J, Bell D, David MP. Acceleration of wound healing by topical application of Honey. An animal model. American Journal of Surgery 1983;145:374-6.

8. Molan PC. The antibacterial activity of honey. The nature of antibacterial activity. Bee World 1992;73:5-28. 9. Cooper RA, Halas E, Davies R, Molan PC, Harding KG (2000). The inhibition of Gram-positive cocci of clinical importance by honey. Paper read at First World Wound Healing Congress, at Melbourne, Australia.
10. Betts JA, Molan PC (2001) A pilot trial of honey as a wound dressing has shown the importance of the way that honey is applied to wounds. Paper read at 11th Conference of the European Wound Management Association, at Dublin, Ireland.

11. Dunford C, Cooper RA, White RJ, Molan PC. The use of honey in wound management. Nurs Stand 2000;15(11):63-8.

12. Natarajan SC, Williamson D, Grey J, Harding KG, Cooper RA. Healing of an MRSA-colonised, hydroxyurea-induced leg ulcer with honey. J Dermatolog Treat. 2001;12(1):33-6.

13. Tanwar R, Gupta J, Asif S, Panwar R, Heralgi R. Aloe Vera and its uses in Dentistry. Indian J Dent Adv. 2011; 3(4): 656-8.

14. Masse JF, Landry RG, et al. Effectiveness of soft laser treatment in periodontal surgery. International Dental Journal. 1993; 43: 121-7.

15. Danhof I 1987. Aloe Through the Ages, Volume 1. Omnimedicus Press.

16. Ansari A, Joshi S, Garad A, Mhatre B, Bagade S, Jain R. A Study to Evaluate the Efficacy of Honey in the Management of Dry Socket. Contemp Clin Dent. 2019;10:52-5. https://doi.org/10.4103/ccd.ccd_283_18

17. Syafilda R, Purba N. Effectiveness Test Of 90\% Aloe Vera Gel Extract For The Time Of Healing PostOdontectomy Wounds In The Department Of Oral And Maxillofacial Surgery Faculty Of Dentistry, Usu. International Journal of Mechanical and Production Engineering Research and Development (IJMPERD) 2020;10(3):4435-44.

18. Nimma LV, Vardhan H, Bairi KJ, Das GM, Bathula $\mathrm{H}$, Vangdoth S. Holistic Healing Through Herbs: Effectiveness of Aloe Vera on Post Extraction Socket Healing. Journal of Clinical and Diagnostic Research 2017;11(3):ZC83-ZC86.

https://doi.org/10.786o/JCDR/2017/21331.9627 
Cite this article as:

Mir H, Shivalingesh KK, Srivastava D, Saleem A, Pathak S. Effectiveness of Honey and Aloe Vera on the Post Extraction Healing Among Young Adults: A Randomized Clinical Trial. Int Healthc Res J. 2021;4(11):OR1-OR6. https://doi.org/10.26440/IHRJ/0411.02390

AUTHOR AFFILIATIONS: (*Corresponding Author)

1. PG Student [https://orcid.org/oooo-0oo2-3233-2654 (Henna Mir), https://orcid.org/oooo-00o2-1755-8436 (Divya Srivastava),

https://orcid.org/oooo-ooo1-690o-0613 (Adeeba Saleem), https://orcid.org/oooo-0oo2-4353-119X (Swati Pathak)]

2. Professor \& Head (ORCID ID: https://orcid.org/oooo-00o2-4636-522X)

Department of Public Health Dentistry, Institute of Dental Sciences, Bareilly, India 